\title{
Role of the rural television programs in diffusion of agricultural innovations in southern Upper Egypt governorates
}

\author{
Al Ghazaly M. A. M. , Murad E. H. E. T., Abo-Elenein M. A. \\ Department of Agricultural Extension and Rural Sociology, Faculty of Agriculture, Al-Azhar University, Assuit, Egypt
}

\begin{abstract}
The research aimed to recognition of views of the surveyed respondents with regard to the degree to which rural television programs play their role in disseminating agricultural innovations in southern Upper Egypt governorates, as well as determining the degree of benefit of the respondents farmers from rural television programs in publishing agricultural innovations, and determining the relationship between the views of the respondents farmers with regard to role of television programs Rural in the dissemination of agricultural innovations, and among the studied independent variables. This research was conducted on a sample of farmers in the southern Upper Egypt governorates: Qena governorate, Luxor, and Aswan, which consisted of 317 researchers who were randomly chosen from among the farmers. Data were collected from the respondents through a personal interview using a questionnaire prepared specifically for this purpose. It was used to display and analyze data, iterations, percentages, $\mathrm{k}^{2}$, and the data was processed and analyzed using the Statistical Programs Group for Social Sciences (SPSS). The research reached the following results: Nearly three quarters of the respondents $(72.2 \%)$ believe that rural television programs play a low role in disseminating agricultural innovations, $14.8 \%$ of the respondents believe that they play an average role, and $13 \%$ of the respondents believe that they play a high role, with a total average score of $1.42 \mathrm{~A}$ degree, which is a low degree of residence, and more than two-thirds of respondents $(70.7 \%)$ have a low level of benefit from rural television programs in their role in publishing agricultural innovations, $17.7 \%$ of respondents benefit moderately, and $11.6 \%$ of respondents benefit high, with a total average calculation of 1.43 degrees, which is a low utilization degree.
\end{abstract}

Keywords: Agricultural innovations, Television programs, southern Upper Egypt governorates.

* Corresponding author: Al Ghazaly M. A. M.,

E-mail address: mohamedelgazaly.4919@azhar.edu.eg 
دور البر امج التليفزيونية الريفية في نثر المستحدثات الزر اعية بمحافظات جنوب الصعيد بجمهورية مصر العربية

\author{
محمد أبو الوفا محمد الغز الي ، السيد حسين السيد طلعت مر اد ، مصطفى عبد الحميد أبو العنين \\ قسم الإرشاد الزر اعي والمجتمع الريفي ، كلية الزراعة ، جامعة الأزهر - فرع أسيوط ، جمهورية مصر العربية
}

المستخلص

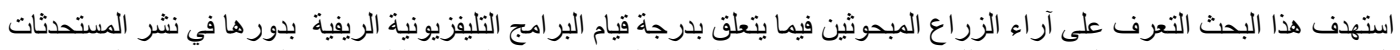

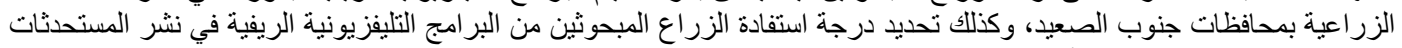

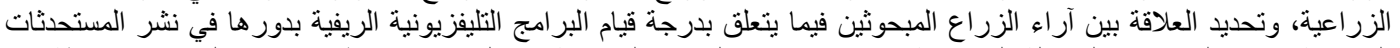

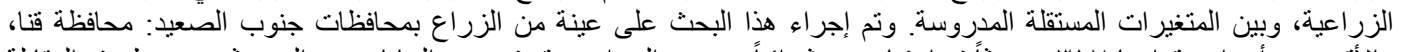

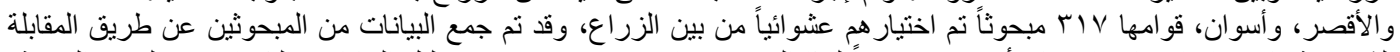

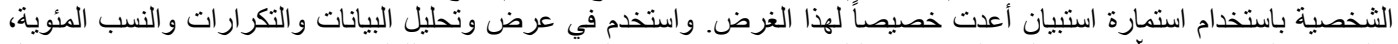

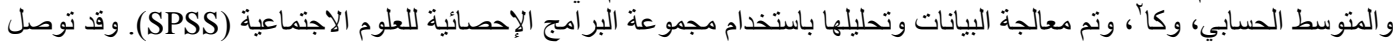

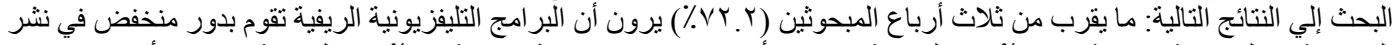

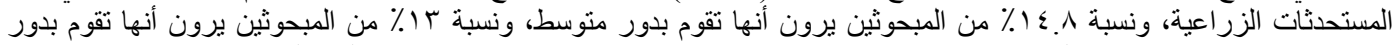

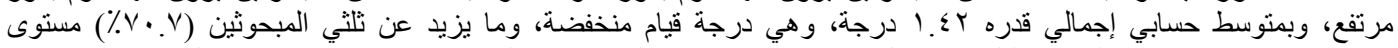

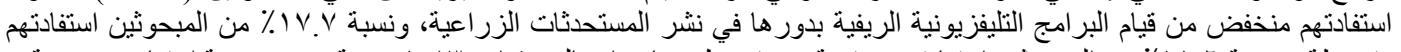

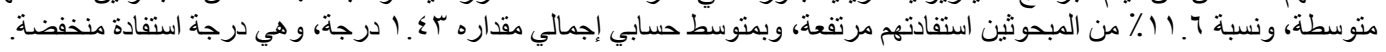
كلمات دالة: المستحدثات الزراعية ، البر امج التليفزيونية ، جنوب الصعيد. 
المجتمع الريفي من اتخاذ قرار مسنتير بشأن أنشطته

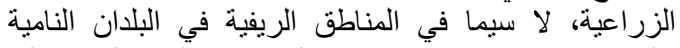

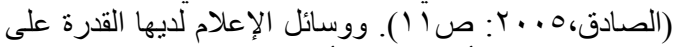

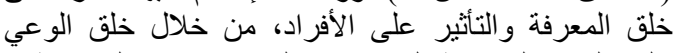

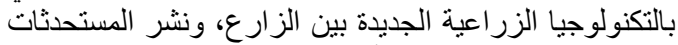

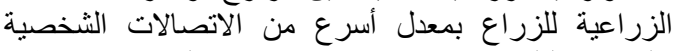

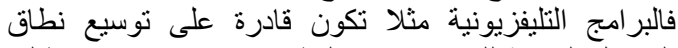

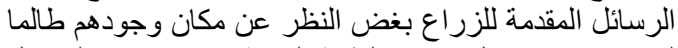

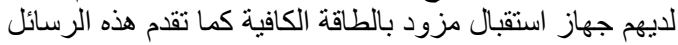
بطريقة جذابة ومثيرة للاهنمام (Ariyo et al., 2013).

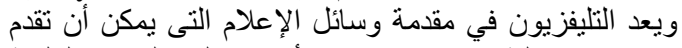

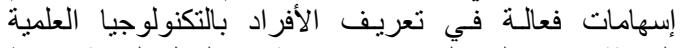

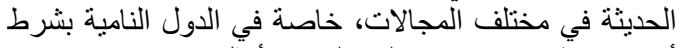

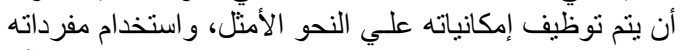

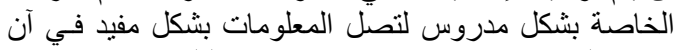

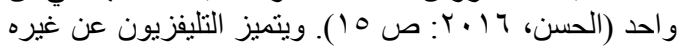

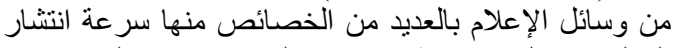

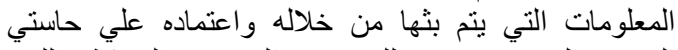

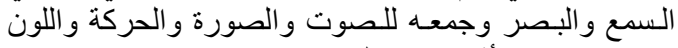

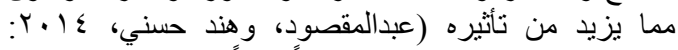

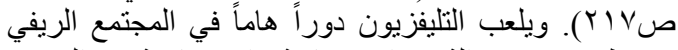

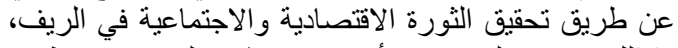

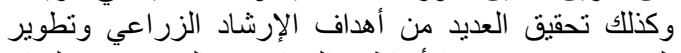

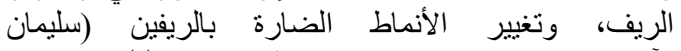

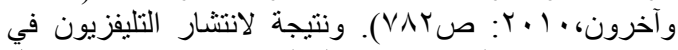

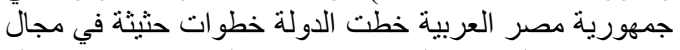

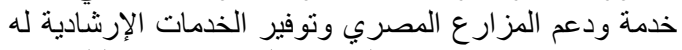

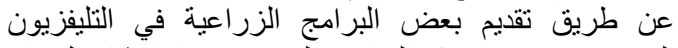

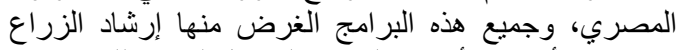

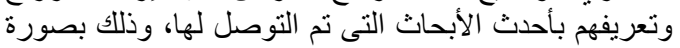

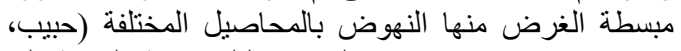
إحداث . . . V

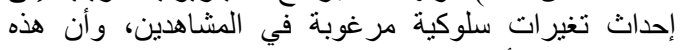

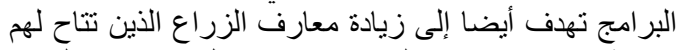

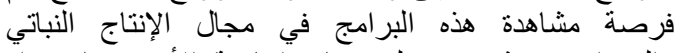

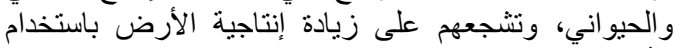
الأساليب العلمية وتطبيق التوصيات الإرشادية الحديثة (محمد،

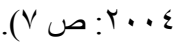

مشكلة البحث

تعتبر محافظات جنوب الصعيد من المحافظات الزراعية

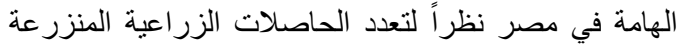

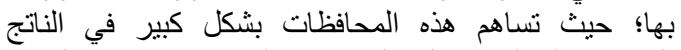

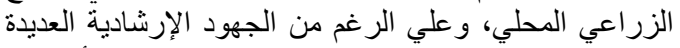

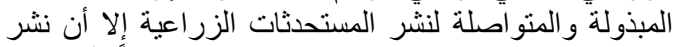

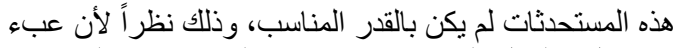

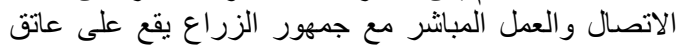

مقدمة

يعد قطاع الزراعة أحد القطاعات الرائدة في مجال تطبيق

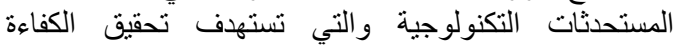

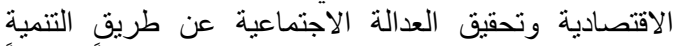

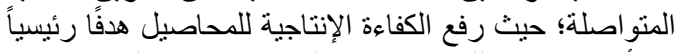

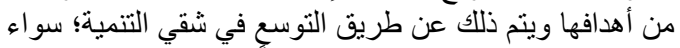

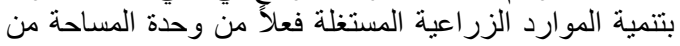

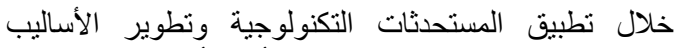

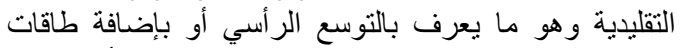

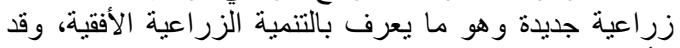

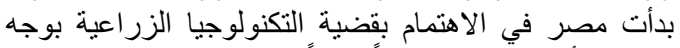

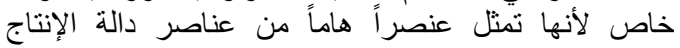

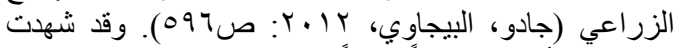

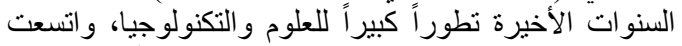

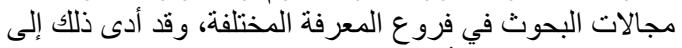

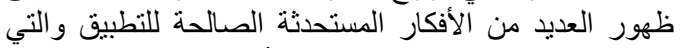

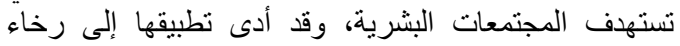

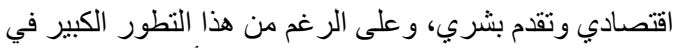

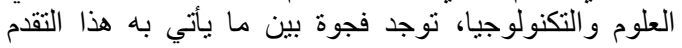

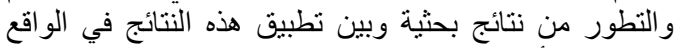

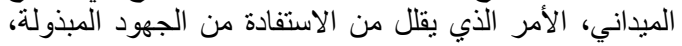

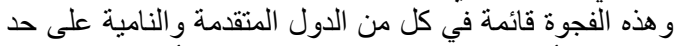

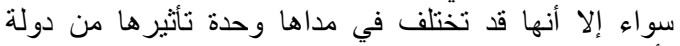

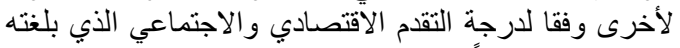

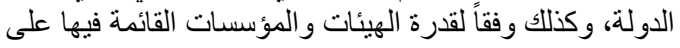

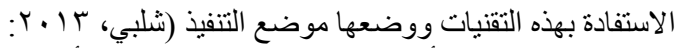

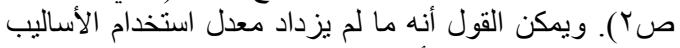
والعناصر الإنتاجية الأكثر عصرية النه مانية المتضدنة للتقدم التقني،

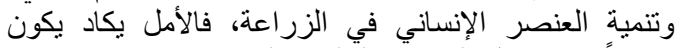

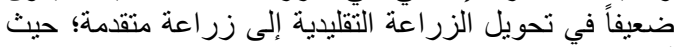

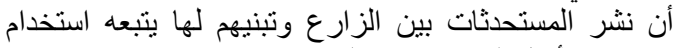

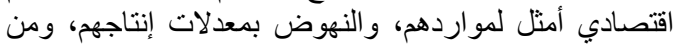

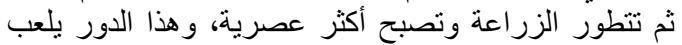

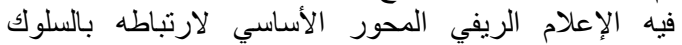

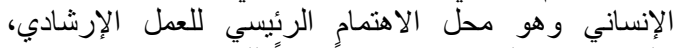

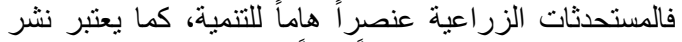

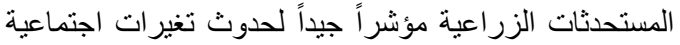

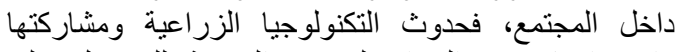

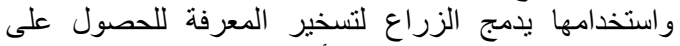
المعلومات حول المستحدثات الأخرى من مصنادر ها المختلفة

لتحسين سبـل العيش (Raj and Bhattacharjee, 2017). ويعتبر الإعلام الريفي بما يقدمه من رسائل ومعلومات من الإن

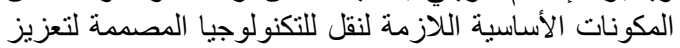

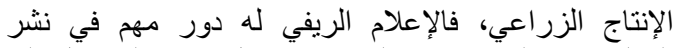

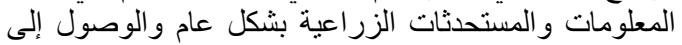

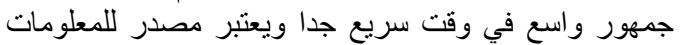

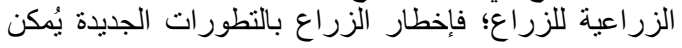


والانفتاح على العالم الخارجية، وملكية وسائل اتصال حديثة،

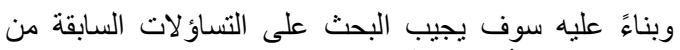
خلال تحقيق الأهداف الآتية: وليه

\section{أهداف البحث}

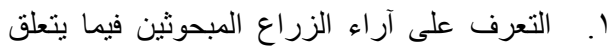

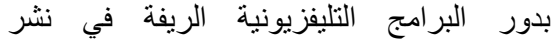
المستحدثات الزر اعية.

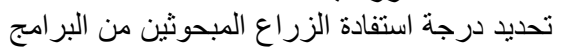

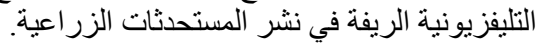

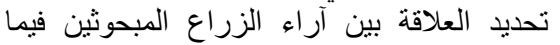

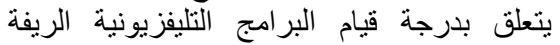

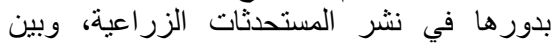

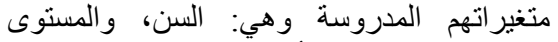

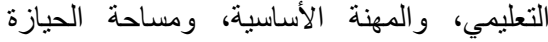
الزراعية، وملكية المشروعات الزراعية واعية، وملكية وسائل اتصال حديثة، والانفتاح على العيثل العالم

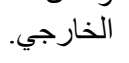

\section{فروض البحث}

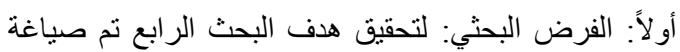

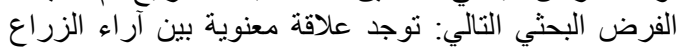

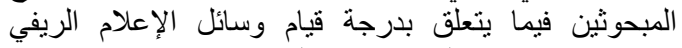

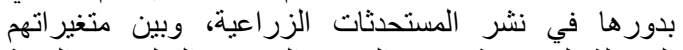

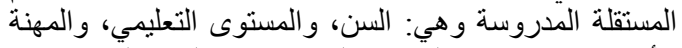

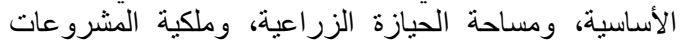

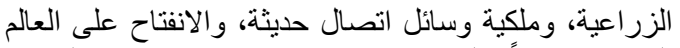

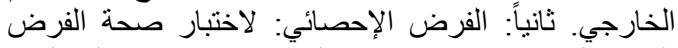

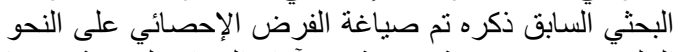

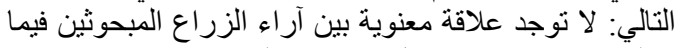

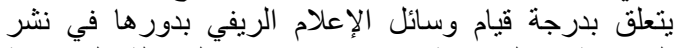

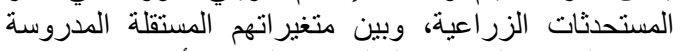

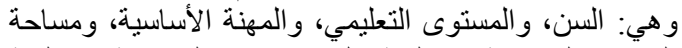

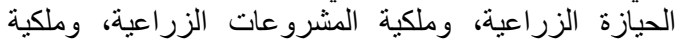
وسائل اتصال حديثة، والانفتاح على العالم الخارجي.

\section{الطريقة البحثية}

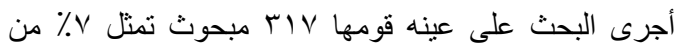

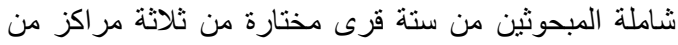

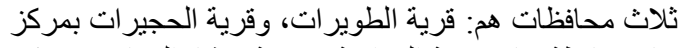

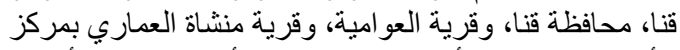

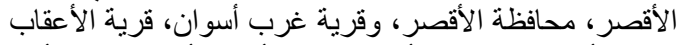

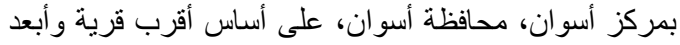
قرية عن المركز. وتم جمع البيانات من المبحوثين عن طريق
المرشدين الزراعيين والقادة المحليين باعتبارهم المهنيون

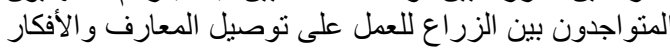

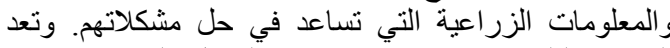

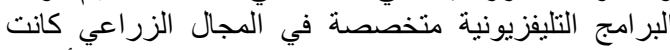

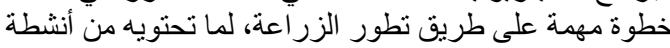

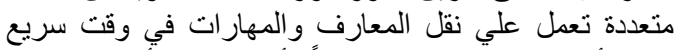

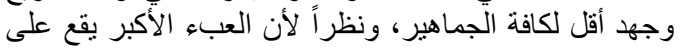

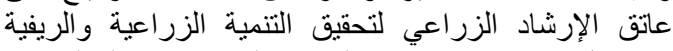

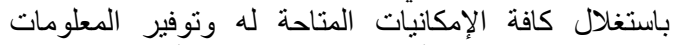

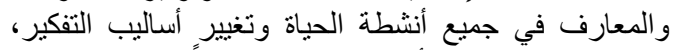

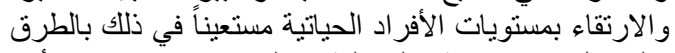

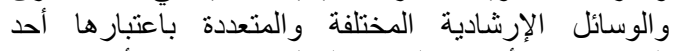

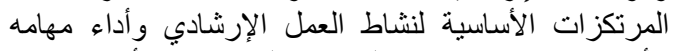

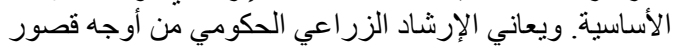

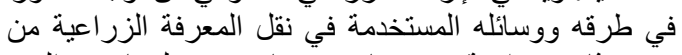

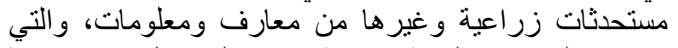

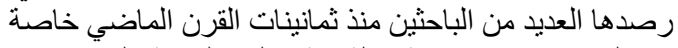

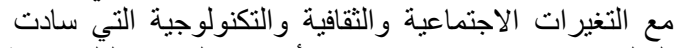

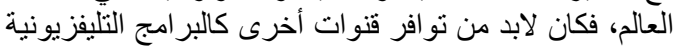

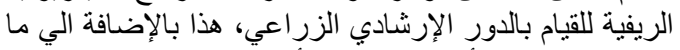

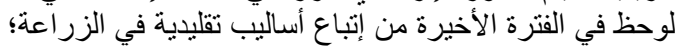

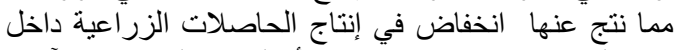

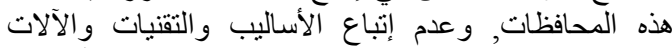

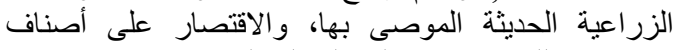

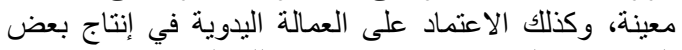

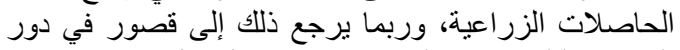

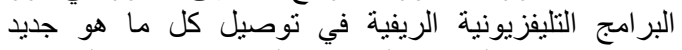

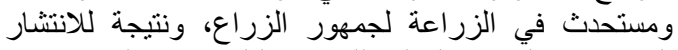

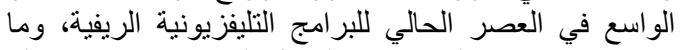

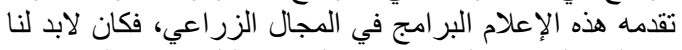

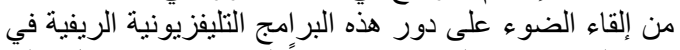

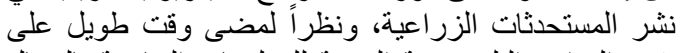

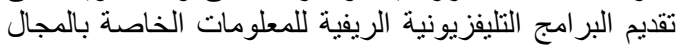

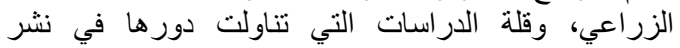

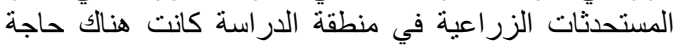

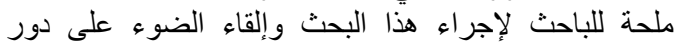

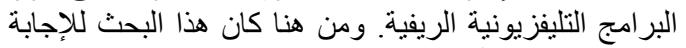

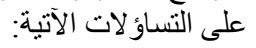

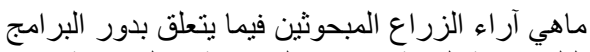

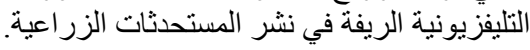

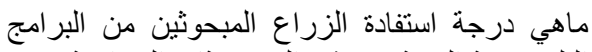
التليفزيونية الريفة في نثر المستحدثات الزئن الزر اعية.

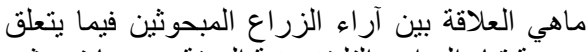

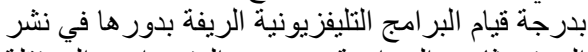

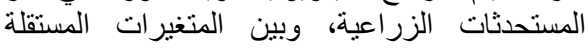

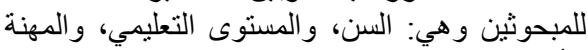

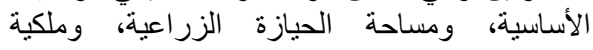


الإجمالي للانفتاح على العالم الخارجي تم جمع الدرجات التي التيات

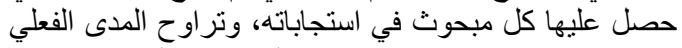

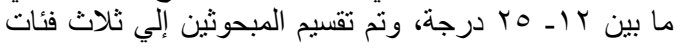

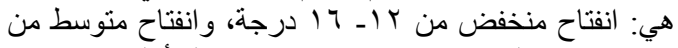

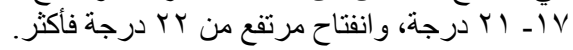

أولاً: دور البرامج التليفزيونية الريفية فى نشر المستحدثات الزراعية

تم قياسه من خلال خمس أنشطة، وأعطيت استجابات (دائما،

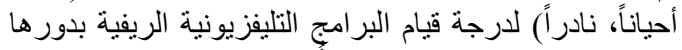

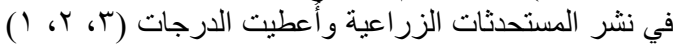

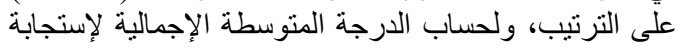

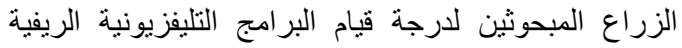

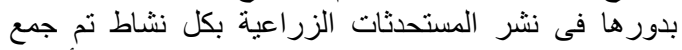

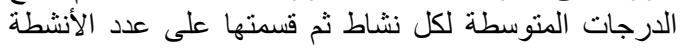

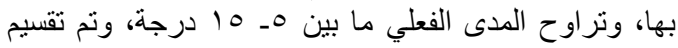

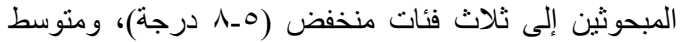

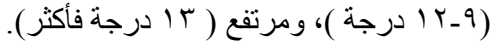

\section{ثانياً: درجة الاستفادة من دور البرامج التليفزيونية الريفية في نشر المستحدثات الزراعية}

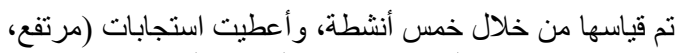

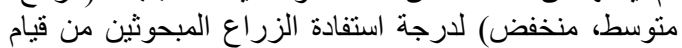

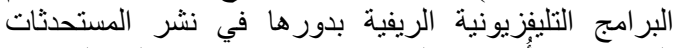

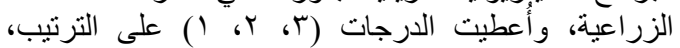

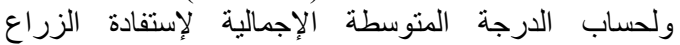

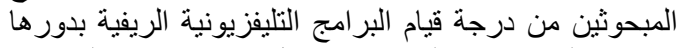

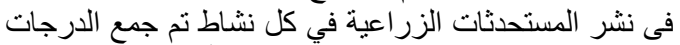

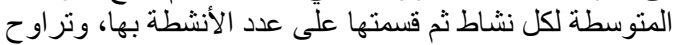

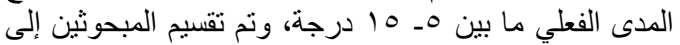

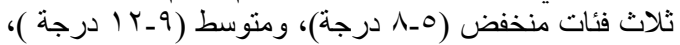
ومرتفع ( با درجة فأكثر ).

\section{النتائج ومناقشتها}

أولاً: المتغيرات المستقلة للمبحوثين

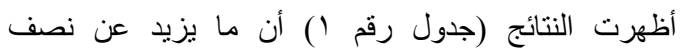

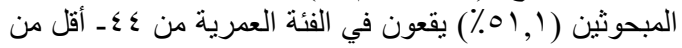

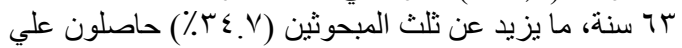

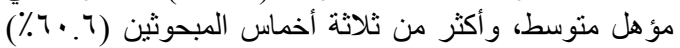

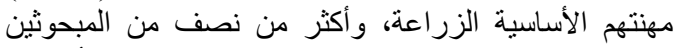

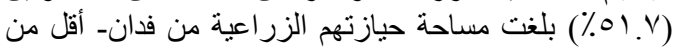

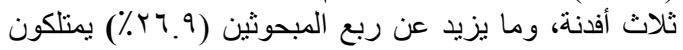

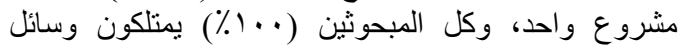

المقابلة الثخصية باستخدام استمارة استبيان أعدت خصيصا

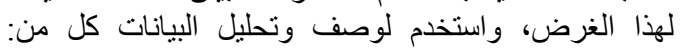

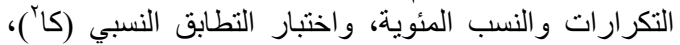

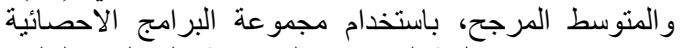

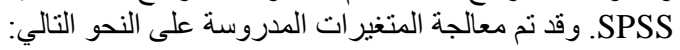

ا ـ السن: نم قياس السن بعدد سنوات عمر المبحوث لأقرب المبرب

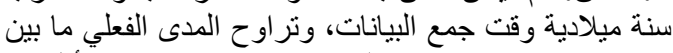

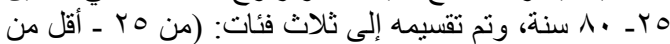

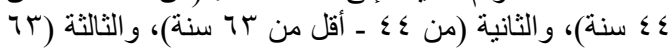

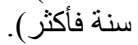

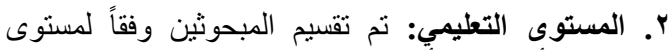

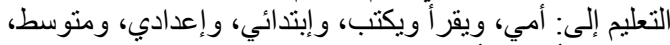

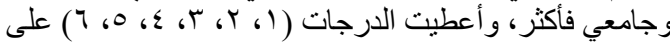
الترتيب.

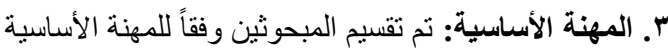

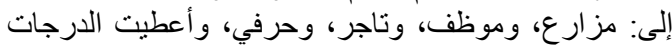

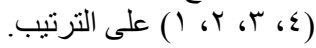

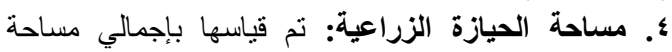

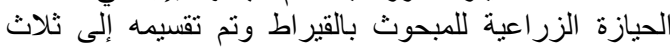

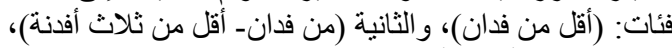
و الثالثة (ثلاث أفدنة فأكثر ).

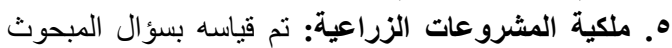

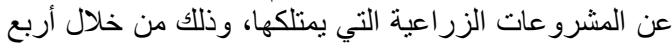

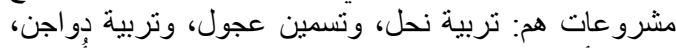

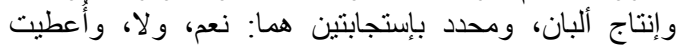

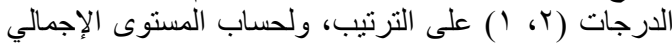

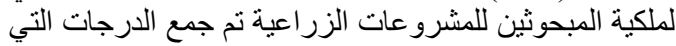

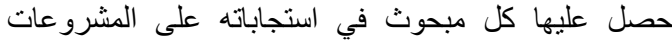

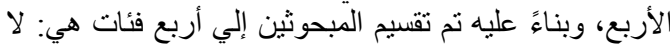

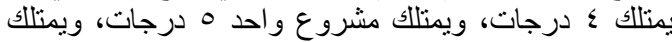

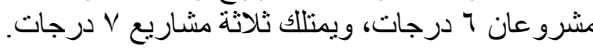

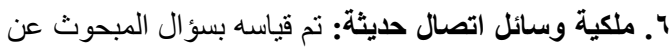

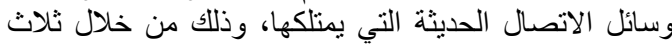

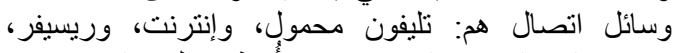

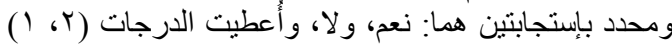

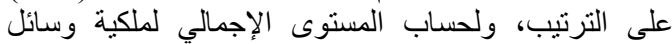

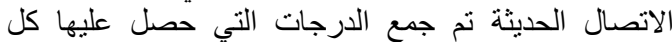

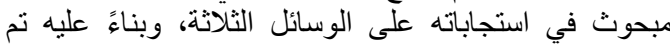

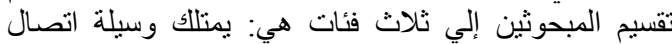

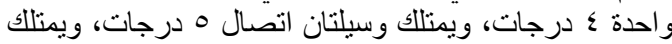
ت الاث وسائل اتصال 7 درجات.

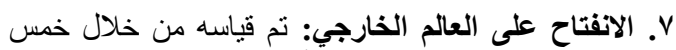

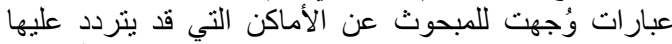

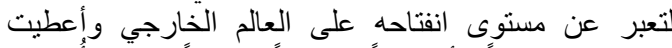

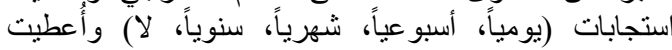

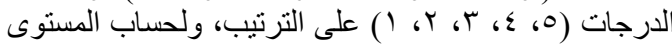




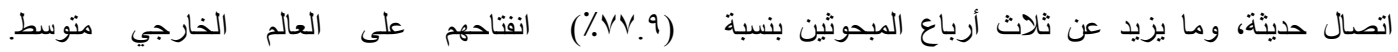
جدول ( ) : التوزيع العدي و النسبي للمبحوثين وفقاً لمتغير اتهم المستقلة المدروسة (ن = VI ).

\begin{tabular}{|c|c|c|c|c|c|}
\hline $\begin{array}{c}\text { النسبة المئوية } \\
\text { (\%) }\end{array}$ & 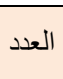 & الخصائص الثخصية & النسبة المئوية & 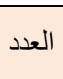 & الخصائص الثخصية \\
\hline צ & $11 \leqslant$ & ع - مساحة الحيازة الزر اعية: & ro 7 & 1) & 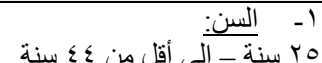 \\
\hline $01 . V$ & $17 \varepsilon$ & من فدانـ أقل من ثناث أفدنة. & 01.1 & IT & ع ـ سنة - إلى أقل من با سنة. \\
\hline r.tr & rq & ثثلاثة أفندة فأكثر. & מ.tr & $V \varepsilon$ & سا7 سنة فأكثر. \\
\hline $1 \cdots$ & TIV & المجموع & $1 \cdots$ & TIV & المجموع \\
\hline & & هـ ملكية المشرو عات الزر اعية: & & & r- - المستوى التعليمي: \\
\hline V). 9 & TYA & لا يمتلك ع درجات. & $1 \cdot .1$ & re & \\
\hline r..9 & 10 & يمنلك مشروع و احد 0 درجات. & ir & rᄉ & يقر أَ ويكتب \\
\hline, 9 & r & يمتلك مشروعان 7 درجات. & $11 . \varepsilon$ & דיץ & ابتدائى. \\
\hline r & 1 & يمتلك ثلاث مشرو عاتV درجات. & 7.7 & r) & إعدادي. \\
\hline & & & $r \varepsilon . V$ & 11. & ن" متوسط. \\
\hline & & & ro.r & $\wedge$. & مؤ هل جامعي فأكثر . \\
\hline $1 \cdots$ & TIV & المجموع & $1 \cdots$ & TIV & المجموع \\
\hline & & 7- ملكية وسائل اتصال حديثة: & & & ب- المهنة الأساسية: \\
\hline A.r & rt & بمتلك وسيلة اتصال و احدة ؛ درجات. & $7 \cdot .7$ & 194 & مز ارع. \\
\hline$\leqslant 9.0$ & $10 \mathrm{~V}$ & بمتلك وسيلتان اتصال ه درجات. & TV.A & $\wedge \wedge$ & موظف. \\
\hline$\varepsilon r . r$ & & يمتلك ثلاث وسائل اتصال 7 درجات. & 7.9 & rt & 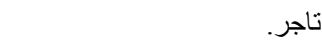 \\
\hline & & & $\varepsilon . \vee$ & 10 & حرفي. \\
\hline $1 \cdots$ & TIV & 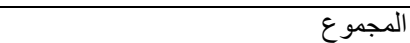 & $1 \cdots$ & TIV & المجموع \\
\hline & & \multirow{4}{*}{\multicolumn{4}{|c|}{ 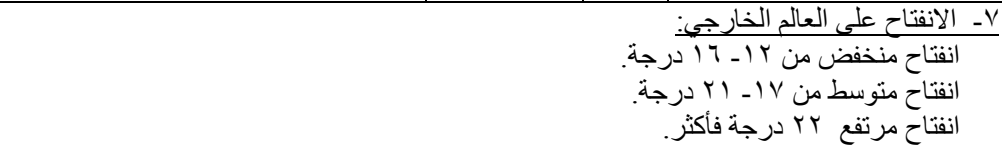 }} \\
\hline$\vee .9$ & ro & & & & \\
\hline$V \vee .9$ & $r \leq V$ & & & & \\
\hline $1 \leqslant .4$ & $\varepsilon 0$ & & & & \\
\hline $1 \cdots$ & TIV & \multicolumn{4}{|r|}{ المجموع } \\
\hline
\end{tabular}

المصدر: استمار ات الاستيبيان

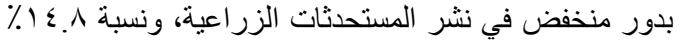

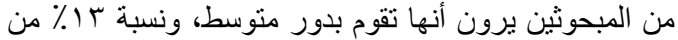
المبحوثين يرون أنها تقوم بدور مرتفع.

ثالثاً: درجة الاستفادة من قيام البرامج التلبفزيونية الريفية بدورها في نشر المستحدثات الزراعية

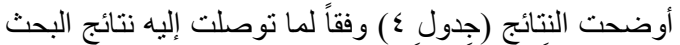

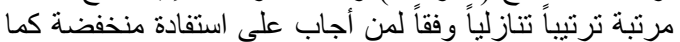

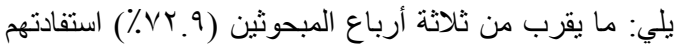

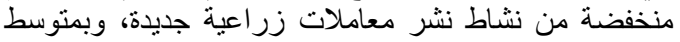

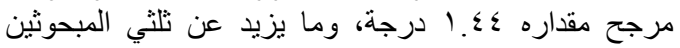

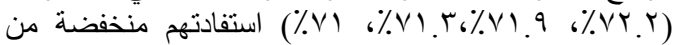

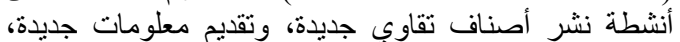

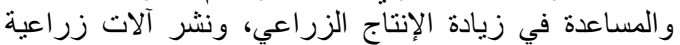

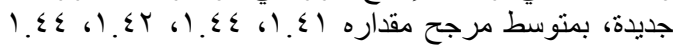
درجة على الترتيب.

\section{ثانياً: درجة قيام البرامج التليفزيونية الريفية بدورها} في نشر المستحدثات الزراماتية

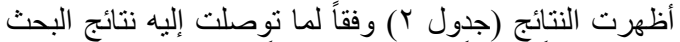

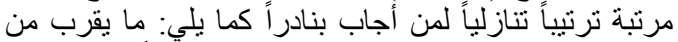

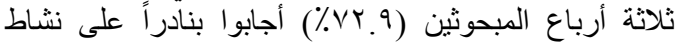

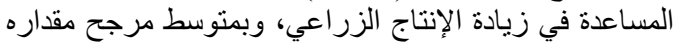

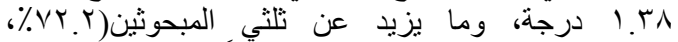

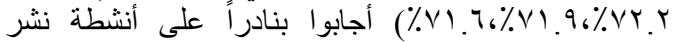

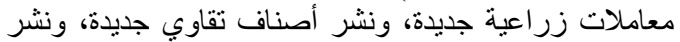

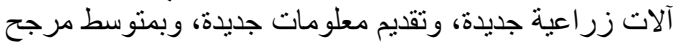

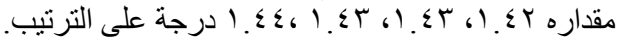

المستوى الإجمالي وفقاً لآراء المبحوثين في قيام البرامج

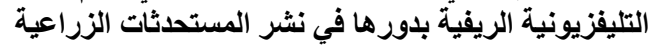

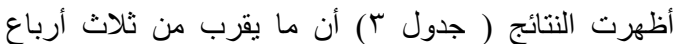

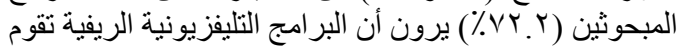


Al Ghazaly et al. / Archives of Agricultural Sciences Journal 3(1) 58-66, 2020.

جدول (r)): التوزيع العددي و النسبي للمبحوثين في درجة قيام البرامج التليفزيونية الريفية بدور ها في نثر المستحدثات الزر اعية من وجهة نظرهم

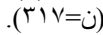

\begin{tabular}{|c|c|c|c|c|c|c|c|c|}
\hline \multirow{3}{*}{ المتوسط المرجح } & \multicolumn{6}{|c|}{ القيام } & \multirow{3}{*}{ الأنشطة } & \multirow{3}{*}{5} \\
\hline & \multicolumn{2}{|c|}{ نادراً } & \multicolumn{2}{|c|}{ أحياناً } & \multicolumn{2}{|c|}{ دائماً } & & \\
\hline & $\%$ & عدد & $\%$ & عدد & $\%$ & عدد & & \\
\hline $1 . \mu \lambda$ & VY. 9 & TM & 17.1 & 01 & 11 & ro & تساعد في زيادة الإنتاج الزر اعي & $T$ \\
\hline $1 . \leqslant Y$ & VY.Y & rrq & 11.9 & $\varepsilon \varepsilon$ & 11.9 & $\varepsilon \varepsilon$ & تنشر معاملات زر اعية جديدة & $r$ \\
\hline $1 . \varepsilon r$ & VY.Y & rrq & $1 \% .9$ & \&) & $1 \leqslant . \wedge$ & $\varepsilon V$ & تنشر أصناف تقاوي جديدة & $r$ \\
\hline $1 . \Sigma T$ & 71.9 & TYA & TH. & $\varepsilon Y$ & $1 \leqslant . \wedge$ & $\sum V$ & تنشر آلات زر اعية جديدة & $\varepsilon$ \\
\hline $1 . \leqslant \varepsilon$ & $V 1.7$ & TYV & IT.Y & $\sum r$ & 10.1 & $\sum \Lambda$ & تقدم معلومات جديدة & o \\
\hline $1 . \varepsilon Y$ & & & & & ال الإجمال & & & \\
\hline
\end{tabular}

جدول (r): المستوى الإجمالي العددي و النسبي وفقاً لآراء المبحوثين في قيـام البر امج التليفزيونيـة الريفيـة بدورها في نثر

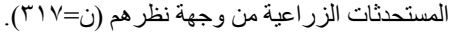

\begin{tabular}{|c|c|c|}
\hline$\%$ & عدد & المستوى الإجمالي لدور البر امج التلبفزيونية الريفية في نشر المستحدثات الزر اعية \\
\hline VY. & rYq & مستوى منخفض (A_0) \\
\hline $1 \leqslant . \wedge$ & $\sum V$ & مستوى متوسط (Y-9 I ) \\
\hline 14 & \&1 & مستوى مرتفع (سا فأكثر) \\
\hline $1 \ldots$ & MIV & 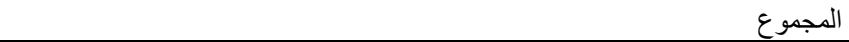 \\
\hline
\end{tabular}

المصدر: استمار ات الاستبيان

جدول (ع): التوزيع العددي و النسبي للمبحوثين في درجة الاستفادة من دور البرامج التليفزيونية الريفية في نشر المستحدثات الزر اعية من وجهة نظر هم (ن) (

\begin{tabular}{|c|c|c|c|c|c|c|c|c|}
\hline \multirow{3}{*}{ المتوسط المرجح } & \multicolumn{6}{|c|}{ الاستفادة } & \multirow{3}{*}{ الأنشطة } & \multirow{3}{*}{ ? } \\
\hline & \multicolumn{2}{|c|}{ منخفض } & \multicolumn{2}{|c|}{ منوسط } & \multicolumn{2}{|c|}{ مرتفع } & & \\
\hline & $\%$ & عدد & $\%$ & عدد & $\%$ & عدد & & \\
\hline $1 . r \Lambda$ & $V Y . q$ & TMI & $1 \cdot .1$ & re & IV & $0 \leqslant$ & تنشر معاملات زر اعية جديدة & 1 \\
\hline $1 . \varepsilon Y$ & VY.Y & rrq & $1 \leqslant . Y$ & $\leqslant 0$ & 15.7 & $\varepsilon r$ & تنشر أصناف تقاوي جديدة & r \\
\hline $1 . \leqslant r$ & 81.9 & TYA & It.r & rq & 10.1 & 0. & تقدم معلومات جديدة & $r$ \\
\hline $1 . \varepsilon r$ & $v 1 . r$ & TYT & 10.0 & $\leqslant 9$ & IT. & $\sum Y$ & تساعد في زيادة الإنتاج الزر اعي & $\varepsilon$ \\
\hline $1 . \leqslant \varepsilon$ & (v) & Tro & $1 \leqslant 0$ & $\leqslant 7$ & $1 \leqslant 0$ & $\leqslant 7$ & تنشر آلات زر اعية جديدة & 0 \\
\hline $1 . \varepsilon r$ & & & & & | - الإجمال & & & \\
\hline
\end{tabular}

\section{المتغيرات المستقلة المدروسة}

أظهرت النتائج (جدول 7) وجود علاقة معنوية عند ا +. • بين

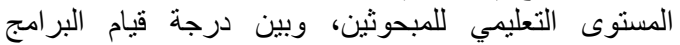

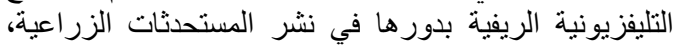

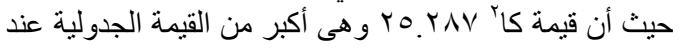

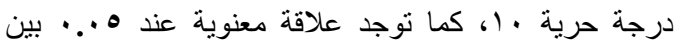

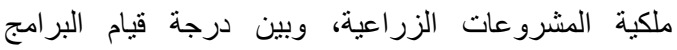

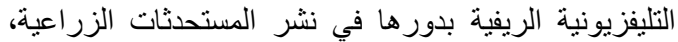

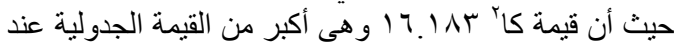

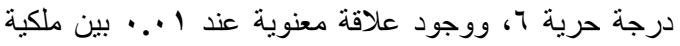

المستوى الإجمالي لاستفادة المبحوثين من دور البرامج التليفزيونية الريفيةً في نشر المستحدثات المبحثين الزراعية دون

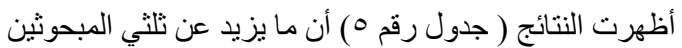
(\%.V.V)

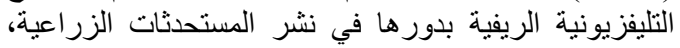

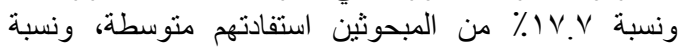
T. 11\% من المبحوثين استفادتهم مرتفعة.

رابعاً: العلاقة بين درجة قيام البرامج التليفزيونية الريفية بدورها في نثر المستحدثات الزراعية ولئ، وبين 
الزستقلة الآتية: السن، والمهنة الأساسية، ومساحة الحيازة

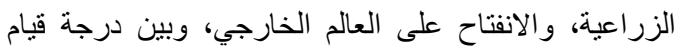

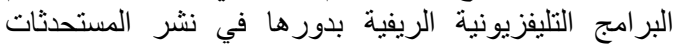

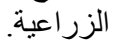

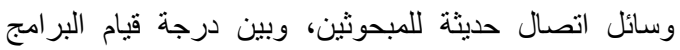

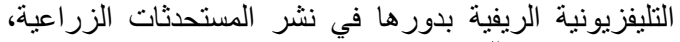

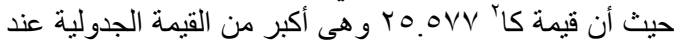

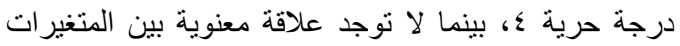

جدول (0): المستوى الإجمالي العددي و النسبي لاستفادة المبحوثين من دور البر امج التليفزيونية الريفية في نشر المستحدثات الزر اعية من وجهة نظرهم

( (r)

\begin{tabular}{|c|c|c|}
\hline$\%$ & عدد & المستوى الإجمالي لاستفادة المبحوثين من دور البر امج التليفزيونية الريفية في نشر المستحدثات الزر اعية \\
\hline $\mathrm{V} \cdot \mathrm{V}$ & YY & مستوى منخفض (A_0) \\
\hline IV.V & 07 & مستوى متوسط (Y-9 (1) \\
\hline 11.7 & rV & مستوى مرتفع (سا فأكثر) \\
\hline $1 \cdots$ & TIV & 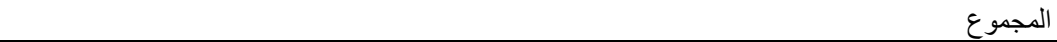 \\
\hline
\end{tabular}

المصدر: استمار ات الاستبيان

جدول (ך): قيم مربع كآبين درجـة قيام البرامح التليفزيونية الريفية بدور ها في نشر المستحدثات الزراعية وبين المتغيرات

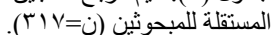

\begin{tabular}{|c|c|c|c|c|}
\hline \multicolumn{3}{|c|}{ درجة القيام ككل } & \multirow{2}{*}{ المتغير ات المستقلة } & \multirow[b]{2}{*}{ 5 } \\
\hline درجة الحرية & قيم كا` المعدلة المحسوبة & قيم كا` المحسوبة & & \\
\hline$\varepsilon$ & & ᄉ. $า \varepsilon$. & 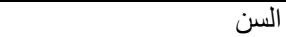 & 1 \\
\hline $1 \cdot$ & **YO. YAV & & المستوى التعليمى & $r$ \\
\hline 7 & A. $\cdot V V$ & & المهنة الأساسية & $r$ \\
\hline$\varepsilon$ & & T.Y.V & مساحة الحيازة الزر اعية & $\varepsilon$ \\
\hline 7 & *17.1Ar & & ملكية المشروعات الزر اعية & 0 \\
\hline$\varepsilon$ & **Yo.OVV & & ملكية وسائل اتصال حديثة & 7 \\
\hline$\varepsilon$ & V.rqq & & الانفتاح على العالم الخارجي & $\mathrm{V}$ \\
\hline
\end{tabular}

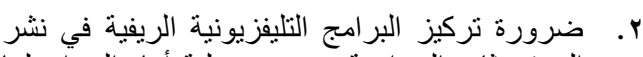

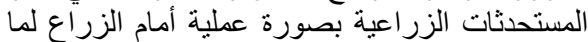
له من تأثير أكبر فى انتشار هاء الزية.

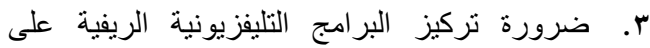

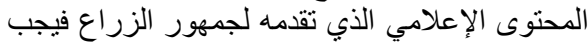

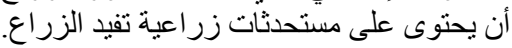

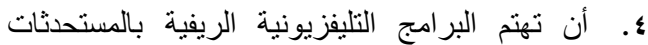

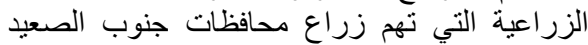
وتناسب المحآصيل المنزر عة بهاء

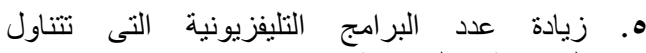
المستحدثات الزر اعية.

\section{قائمة المراجع أولاً: المراجع باللغة العربية المراية}

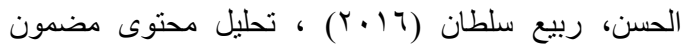

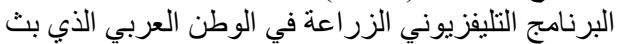

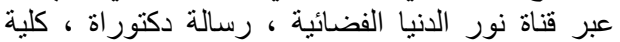
الزر اعة، جامعة القاهرة ، جمهورية مصر العربية.
وبناءً على ما أظهرته النتائج سالفة الذكر بمكن رفض أجزاء

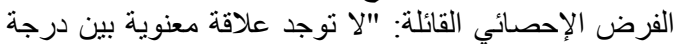

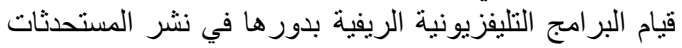

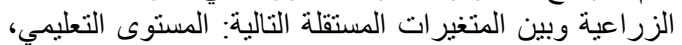

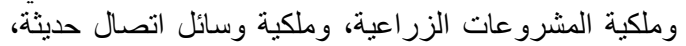

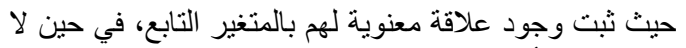

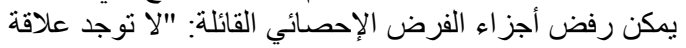

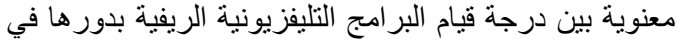

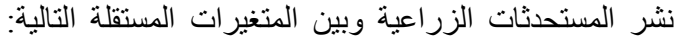

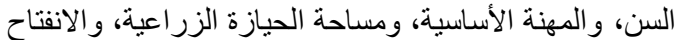

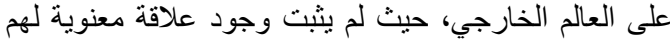

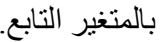

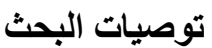

في ضوء النتائج التي تم التوصل إليها في هذا البحث فإنه أمكن استخلاص التوصيات التالية:

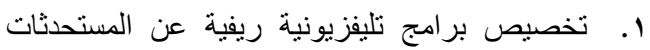
الزر اعية لزر اع محافظات جنوب الصعيد. 


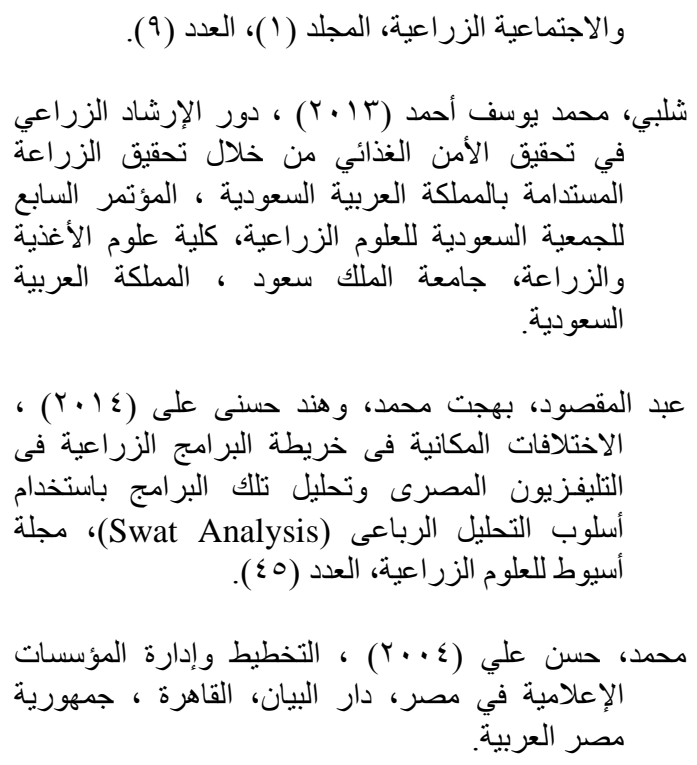

Ariyo, O. C., Ariyo, M. O., Okelola, O. E., Aasa, O. S., Olakunle Gbenga Awotide, Angela Aaron and Oni, O. O. (2013), Assessment of the role of mass media in the dissemination of agricultural technologies among farmers in Kaduna North local government area of Kaduna State, Nigeria, Federal College of Forestry Mechanization, Afaka, Kaduna, Kaduna State, Nigeria.

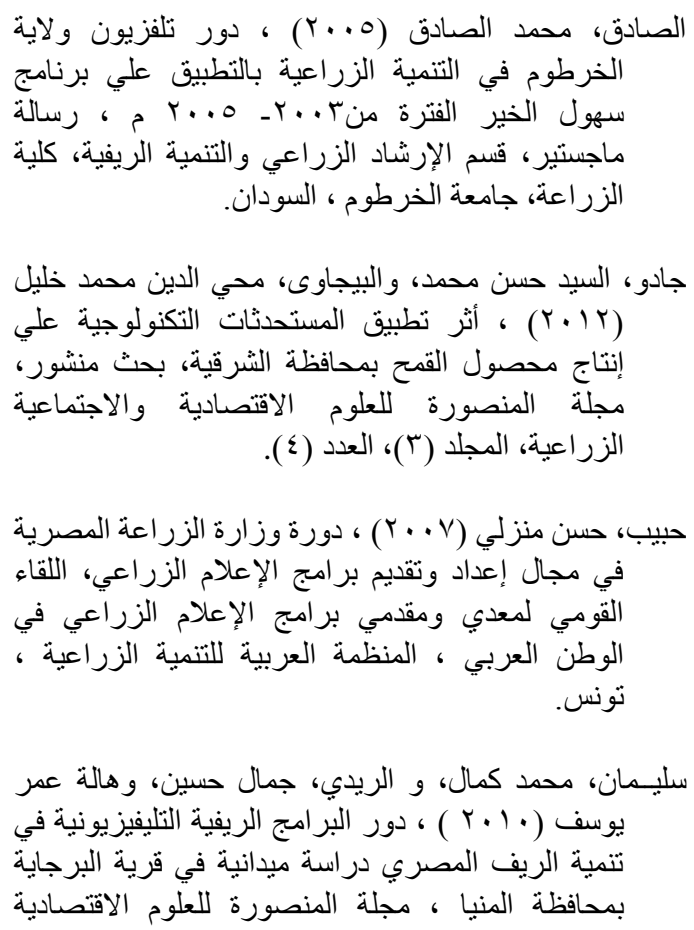

\section{ثانياً: مراجع باللغة الإنجليزية}

Raj, S. and Bhattacharjee, S. (2017), Agricultural Innovation Systems: Fostering Convergence for Extension, Bulletin No. 2, National Institute of Agricultural Extension Management (MANAGE), Rajendranagar, Hyderabad - 500 030, Telangana State, India. 